\title{
Unsteady Flow of a Dusty Gas Through a Horizontal Pipe with Time Varying Pressure Gradient
}

\author{
Madan Lal, Swati Agarwal
}

\begin{abstract}
In the present paper, the unsteady flow of a dusty gas through a pipe under the effect of the linear and exponential pressure gradient is established. Firstly the equation of motion of the fluid and dust particles is considered and then converts it into the Bessel equation by introducing two different parameters. Using the solution of the Bessel equation, the velocity of the gas and dust particles is obtained and shown graphical representation.It is found that the velocities increases as one move towards the axis of the pipe. Under the linear pressure gradient, the velocity of the gas is greater than the velocity of dust particles. As time progresses velocity increases and under exponential pressure gradient the velocity of the dust particles is greater than the velocity of the gas. As time progresses velocity decreases.
\end{abstract}

Keywords: Bessel equation, Dust particles, Fluid, Pressure gradient, Velocity.

\section{INTRODUCTION}

M.H. Hamdan and R.M. Barron [4] examined a dusty gas flow model in porous media. This model has direct applicability to irrigation problems. P.G.Saffman [6] proposed the first phenomenology if the dust is fine then the relaxation time would be relatively small and the gas flow would get destabilized whereas if the dust is coarse then the relaxation time would be relatively large and the gas flow would be stabilized. In an alternate phenomenology, P.Samba Siva Rao [7] obtained analytical expressions for the velocities of the fluid and dust particles in two different cases. M.S.Abu Zaytoon and M.H.Hamdan [5] analyzed a Saffman's dusty gas flow through porous media. Praveen Sharma and C.L. Varshney [8] observed thevariations of velocity of gas and dust particles for different values of parameters such as magnetic field, thermal dispersion and volume fraction. M.Allan Fathi, Qatanani Naji, Barghouthi Imad and M. Takatka Khaled [3] described the influence of the Reynold number, the permeability and drag coefficient on the horizontal velocity. A. Damesh Rebhi [1] focused the flow of a viscous incompressible gas with uniformly distributed dust particles across an isothermal cylinder. R.K.Gupta [9] expressed that the movement of gas is faster than the particles through a channel under a constant pressure gradient.

Revised Manuscript Received on January 30, 2020.

* Correspondence Author

Dr. Madan Lal*, Head of Applied Mathematics Department, M.J.P.Rohilkhand University Bareilly (U.P.) India.

Swati Agarwal, Applied Mathematics Department, M.J.P.Rohilkhand University Bareilly (U.P.) India.

(C) The Authors. Published by Blue Eyes Intelligence Engineering and Sciences Publication (BEIESP). This is an open access article under the CC-BY-NC-ND license http://creativecommons.org/licenses/by-nc-nd/4.0/
G.Narsimlu, L.Anand Babu and P.Raji Reddy [2] observed that the velocity decreases with the decrease of $n$ and velocity of the dust particle is greater than the clean dust particle. In the present paper unsteady flow of a dusty gas under the effect of linear and exponential pressure gradient with uniform distribution has been obtained and shown in figures graphically.

\section{MATHEMATICAL FORMULATION OF A PROBLEM}

The equations of unsteady motion of a dusty, viscous incompressible fluid are

$\frac{\partial \mathbf{u}}{\partial \mathrm{t}}+(\mathbf{u} \cdot \nabla) \mathbf{u}=-\frac{\nabla \mathrm{P}}{\rho}+v \nabla^{2} \mathbf{u}+\frac{\mathrm{KN}}{\rho}(\mathbf{v}-\mathbf{u})$

$\operatorname{div} \mathbf{u}=\mathbf{0}$

$\mathrm{m}\left[\frac{\partial \mathbf{v}}{\partial t}+(\mathbf{v} \cdot \nabla) \mathbf{v}\right]=\mathrm{K}(\mathbf{u}-\mathbf{v})$

$\frac{\partial \mathbf{N}}{\partial t}+\operatorname{div}(\mathrm{Nv})=0$

Where

$\mathbf{u}$ and $\mathbf{v}$ denote the velocity of fluid and dust particles respectively, $\mathrm{P}$ is the fluid pressure, $\mathrm{m}$ is the mass of dust particles, $\mathrm{N}$ is the number density, $\mathrm{K}$ is the Stoke's resistance coefficient, $\rho$ is the density and $v$ is the kinematic viscosity.Consider a horizontal pipe of radius $r_{0}$ Under the effect of linear and exponential pressure gradient, the unsteady flow of gas with uniform distribution is investigated. The velocity distribution of gas and dust particles are defined respectively as

$$
\begin{aligned}
& \mathrm{u}_{\mathrm{x}}=0, \mathrm{u}_{\mathrm{y}}=0, \mathrm{u}_{\mathrm{z}}=\mathrm{U}(\mathrm{r}, \mathrm{t}) \\
& \mathrm{v}_{\mathrm{x}}=0, \mathrm{v}_{\mathrm{y}}=0, \mathrm{v}_{\mathrm{z}}=\mathrm{V}(\mathrm{r}, \mathrm{t})
\end{aligned}
$$

In terms of cylindrical coordinates $(r, \theta, z)$ the equations (1) and (3) reduce to

$$
\begin{gathered}
\frac{\partial \mathrm{U}}{\partial \mathrm{t}}=-\frac{1}{\rho} \frac{\partial \mathrm{P}}{\partial \mathrm{z}}+v\left(\frac{\partial^{2} \mathrm{U}}{\partial \mathrm{r}^{2}}+\frac{1}{\mathrm{r}} \frac{\partial \mathrm{U}}{\partial \mathrm{r}}\right)+\frac{\mathrm{KN}}{\rho}(\mathbf{V}-\mathbf{U}) \\
\mathrm{m} \frac{\partial \mathbf{V}}{\partial t}=\mathrm{K}(\mathbf{U}-\mathbf{V})
\end{gathered}
$$

Differentiating partially equation (7) w.r.t ' $t$ ' and eliminating $\mathrm{V}$ from (7) and (8), we get

$$
\begin{aligned}
& \frac{\partial^{2} \mathrm{U}}{\partial \mathrm{t}^{2}}=\frac{\partial}{\partial t}\left(-\frac{1}{\rho} \frac{\partial \mathrm{P}}{\partial \mathrm{z}}\right)+v \frac{\partial}{\partial t}\left(\frac{\partial^{2} \mathrm{U}}{\partial \mathrm{r}^{2}}+\frac{1}{\mathrm{r}} \frac{\partial \mathrm{U}}{\partial \mathrm{r}}\right)-\left(\frac{\mathrm{KN}}{\rho}+\frac{\mathrm{K}}{\mathrm{m}}\right) \frac{\partial \mathrm{U}}{\partial \mathrm{t}}- \\
& \frac{\mathrm{K}}{\mathrm{m}}\left[\frac{1}{\rho} \frac{\partial \mathrm{P}}{\partial \mathrm{z}}-v\left(\frac{\partial^{2} \mathrm{U}}{\partial \mathrm{r}^{2}}+\frac{1}{\mathrm{r}} \frac{\partial \mathrm{U}}{\partial \mathrm{r}}\right)\right]
\end{aligned}
$$

$$
\text { CaseI : Assuming }-\frac{1}{\rho} \frac{\partial \mathrm{P}}{\partial \mathrm{z}}=\mathrm{a}+\mathrm{bt}, \mathrm{R}=\frac{\mathrm{r}}{\mathrm{r}_{0}} \text {, }
$$

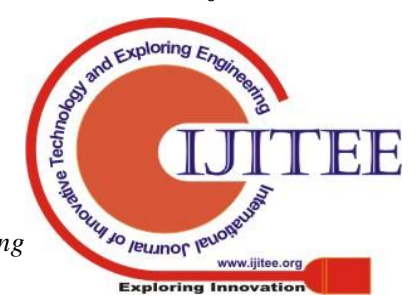


$U(R, t)=f(R)(a+b t)$,

and $\quad V(R, t)=g(R)(a+b t)$

Initial and Boundary conditions are

$$
\begin{array}{ll}
\mathrm{f}(0)=0, \mathrm{~g}(0)=0 \quad ; \mathrm{r}=0, \mathrm{t}=0 \\
\mathrm{f}(1)=0, \mathrm{~g}(1)=0 \quad ; \mathrm{r}=\mathrm{r}_{0}, \mathrm{t}>0
\end{array}
$$

Using equations (10) (11) (12) and (13) then (8) and (9) becomes

$$
\begin{aligned}
& \mathrm{g}\left(1+\frac{\mathrm{cb}}{\mathrm{a}}\right) \\
& \frac{v}{\mathrm{r}_{0}{ }^{2}}\left(\frac{d^{2} \mathrm{f}}{d \mathrm{R}^{2}}+\frac{1}{\mathrm{R}} \frac{d \mathrm{f}}{d \mathrm{R}}\right) \mathrm{b}-\mathrm{fb}\left(\frac{\mathrm{KN}}{\rho}+\frac{\mathrm{K}}{m}\right)+\frac{\mathrm{K}(\mathrm{a})}{m}[1+ \\
& \nu \mathrm{r} 02 d 2 \mathrm{f} d \mathrm{R} 2+1 \mathrm{R} d \mathrm{f} d \mathrm{R}+\mathrm{b}=0
\end{aligned}
$$

After simplification equation (16) reduce to Bessel equation as

$$
\frac{d^{2} \mathrm{f}}{d \mathrm{R}^{2}}+\frac{1}{\mathrm{R}} \frac{d \mathrm{f}}{d \mathrm{R}}+\mathrm{n}^{2}(\varepsilon-\mathrm{f})=0
$$

Where $\quad \mathrm{n}^{2}=\frac{\mathrm{br}_{0}{ }^{2}(l+1)}{v(\mathrm{a}+\mathrm{cb})} \quad$ and $\varepsilon=\frac{\mathrm{a}+\mathrm{\tau b}}{\mathrm{b}(l+1)}$ are two dimensionless parameters; $\tau=\mathrm{m} / \mathrm{k}$ is the relaxation time of dust particles; $l=\frac{\mathrm{mN}}{\rho}$ is the mass concentration of the dust particles.

The solution of Bessel equation (17) is given by

$\mathrm{f}(\mathrm{R})=\mathrm{C}_{1} \mathrm{~J}_{0}(\mathrm{nR})+\mathrm{C}_{2} \mathrm{Y}_{0}(\mathrm{nR})-\varepsilon$

Where $\mathrm{C}_{1}$ and $\mathrm{C}_{2}$ are arbitrary constant and $\mathrm{J}_{0}(\mathrm{nR})$ and $\mathrm{Y}_{0}(\mathrm{nR})$ are Bessel functions of first and second kind of order zero.

Consider function which satisfy the boundary conditions, $\mathrm{f}(\mathrm{R})=\varepsilon\left(\frac{\mathrm{J}_{0}(\mathrm{nR})}{\mathrm{J}_{0}(\mathrm{n})}-1\right)$

Where $\mathrm{J}_{0}(\mathrm{nR}) \approx 1-\frac{(\mathrm{nR})^{2}}{4}$

(20), the equation (19) reduce to

Using

$\frac{\epsilon \mathrm{n}^{2}\left(1-\mathrm{R}^{2}\right)}{\left(4-\mathrm{n}^{2}\right)}$

On simplifying equations (11) and (12) are given by

$\mathrm{U}(\mathrm{R}, \mathrm{t})=\frac{\epsilon \mathrm{n}^{2}\left(1-\mathrm{R}^{2}\right)}{\left(4-\mathrm{n}^{2}\right)}(\mathrm{a}+\mathrm{bt})$

$\mathrm{V}(\mathrm{R}, \mathrm{t})=\frac{\epsilon \mathrm{an}^{2}\left(1-\mathrm{R}^{2}\right)(\mathrm{a}+\mathrm{bt})}{\left(4-\mathrm{n}^{2}\right)(\mathrm{a}+\tau \mathrm{b})}$

Case II: Assuming $-\frac{1}{\rho} \frac{\partial \mathrm{P}}{\partial \mathrm{z}}=\frac{1}{\beta} \mathrm{e}^{-\mathrm{t} / \beta} ; \beta>0$ is a parameter.

$$
\mathrm{W}_{1}(\mathrm{R}, \mathrm{t})=\emptyset_{1}(\mathrm{R}) \mathrm{e}^{-\mathrm{t} / \beta},
$$

$$
W_{2}(R, t)=\emptyset_{2}(R) e^{-t / \beta}
$$

Initial and Boundary

conditions

$\emptyset_{1}(0)=0, \emptyset_{2}(0)=0 ; \mathrm{r}=0, \mathrm{t}=0$

$\emptyset_{1}(1)=0, \emptyset_{2}(1)=0 ; \mathrm{r}=\mathrm{r}_{0}, \mathrm{t}>0$

Using equ

$\emptyset 21-\tau \beta$

$\frac{\emptyset_{1}}{\beta^{2}}=-\frac{1}{\beta^{2}}-\frac{v}{\mathrm{r}_{0}^{2} \beta}\left(\frac{d^{2} \emptyset_{1}}{d \mathrm{R}^{2}}+\frac{1}{\mathrm{R}} \frac{d \emptyset_{1}}{d \mathrm{R}}\right)+\frac{\emptyset_{1}}{\beta}\left(\frac{\mathrm{KN}}{\rho}+\frac{\mathrm{K}}{m}\right)+\frac{\mathrm{K}}{m}\left[\frac{1}{\beta}+\right.$

$\left.\frac{v}{\mathrm{r}_{0}^{2}}\left(\frac{d^{2} \emptyset_{1}}{d \mathrm{R}^{2}}+\frac{1}{\mathrm{R}} \frac{d \emptyset_{1}}{d \mathrm{R}}\right)\right]$

After simplification equation (30) reduce to Bessel equation as

$\frac{1}{\mathrm{R}} \frac{d \emptyset_{1}}{d \mathrm{R}}+\mathrm{n}^{2}\left(\emptyset_{1}+\Omega\right)=0$
Where $\mathrm{n}^{2}=\frac{\mathrm{r}_{0}{ }^{2}}{v \beta}\left(1-\frac{l \beta}{\tau-\beta}\right)$ and $\Omega=\frac{(\tau-\beta)}{(\tau-l \beta-\beta)}$

are

two dimensionless parameters.

The solution of Bessel equation (31) is given by $\emptyset_{1}(R)=$ $\mathrm{C}_{1} \mathrm{~J}_{0}(\mathrm{nR})+\mathrm{C}_{2} \mathrm{Y}_{0}(\mathrm{nR})-\Omega$

(32) Where $\mathrm{C}_{1}$ and $\mathrm{C}_{2}$ are arbitrary constant and $\mathrm{J}_{0}(\mathrm{nR})$ and $\mathrm{Y}_{0}(\mathrm{nR})$ are Bessel functions of first and second kind of order zero. Consider a function which satisfy the boundaryconditions $\emptyset_{1}(\mathrm{R})=\Omega\left(\frac{\mathrm{J}_{0}(\mathrm{nR})}{\mathrm{J}_{0}(\mathrm{n})}-1\right)$

Where $\mathrm{J}_{0}(\mathrm{nR}) \approx 1-\frac{(\mathrm{nR})^{2}}{4}$

Using (34), the equation (33) reduce to

$\emptyset_{1}(\mathrm{R})=\frac{\Omega \mathrm{n}^{2}\left(1-\mathrm{R}^{2}\right)}{\left(4-\mathrm{n}^{2}\right)}$

On simplifying equations (25) and (26) are given by

$W_{1}(R, t)=\frac{\Omega n^{2}\left(1-R^{2}\right)}{\left(4-n^{2}\right)} e^{-t / \beta}$

$\mathrm{W}_{2}(\mathrm{R}, \mathrm{t})=\frac{\Omega \mathrm{n}^{2}\left(1-\mathrm{R}^{2}\right)}{\left(4-\mathrm{n}^{2}\right)} \frac{\beta}{(\beta-\tau)} \mathrm{e}^{-\mathrm{t} / \beta}$

\section{RESULT AND DISCUSSION}

Represntative results for velocity of gas and velocity of dust particles as a function of radial coordinate and time under the effect of linear and exponential pressure gradient along a pipe are obtained by taking $a=1, b=1$. Additionally we have computed the velocities of gas and dust particles separately at time $\mathrm{t}=0.1$ and $\mathrm{t}=0.2$. In Table $\mathrm{I}$, for the case linear pressure gradient, velocity of the gas $U$ is more than the velocity of dust particles. In Table II and Table III, as the value of $\mathrm{R}$ increases velocities of gas and dust particles decreases. From Fig. 1 it is observed that velocity of gas is more than the velocity of dust particles. As the value of $R$ increases, velocity of the gas or dust particles decreases i.e, velocity increases as one move towards the axis of pipe. If we take multiple cylinders of different radius it is observed that the velocity of gas or dust particles is greater in cylinder with greater radius for same value of $r$ i.e., as the value of $n$ decreases, velocity also decreases. Fig. 2 and 3 depict that as the time progresses, the velocity increases. In Table IV, for the case exponential pressure gradient, velocity of the dust particles $\mathrm{W}_{2}$ is more than the velocity of gas $\mathrm{W}_{1}$. In Table $\mathrm{V}$ and Table VI, as the value of $\mathrm{R}$ increases velocities of gas and dust particles decreases. Fig. 4 reveals that velocity of dust particles is more than the velocity of gas. As the value of $\mathrm{n}$ decreases velocity decreases and velocity increases as one move towards the axis of pipe. Fig. 5 and 6 depict that as the time progresses the velocity decreases.

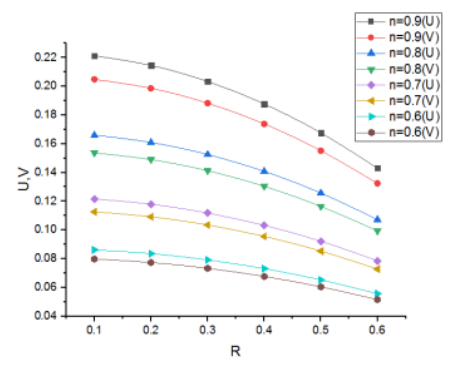

Fig. 1. Velocity of gas and dust particles for distinct values of $\mathbf{n}$ under linear pressure gradient.

Published By: 


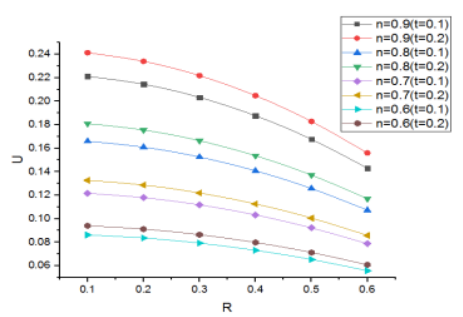

Fig. 2. Velocity of gas for distinct values of $n$ w.r.t. time t.

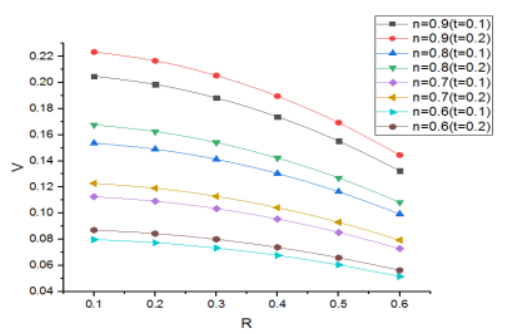

Fig.3.Velocity of dust particles for distinct values of $\mathbf{n}$ w.r.t. time t.

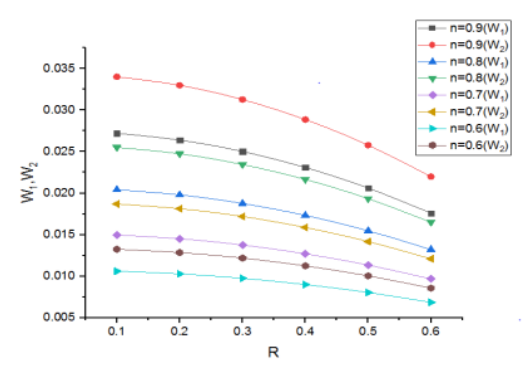

Table I: Velocities of gas and dust particles under linear pressure gradient

\begin{tabular}{|c|c|c|c|c|c|c|c|c|}
\hline & \multicolumn{5}{|c|}{$\mathrm{U}$} & \multicolumn{4}{c|}{$\mathrm{V}$} \\
\hline $\mathrm{R}$ & $\mathrm{n}=0.9$ & $\mathrm{n}=0.8$ & $\mathrm{n}=0.7$ & $\mathrm{n}=0.6$ & $\mathrm{n}=0.9$ & $\mathrm{n}=0.8$ & $\mathrm{n}=0.7$ & $\mathrm{n}=0.6$ \\
\hline 0.1 & 0.221214 & 0.165943 & 0.121621 & 0.086163 & 0.204828 & 0.153651 & 0.112612 & 0.079781 \\
\hline 0.2 & 0.21451 & 0.160914 & 0.117935 & 0.083552 & 0.19862 & 0.148949 & 0.109199 & 0.077363 \\
\hline 0.3 & 0.203338 & 0.152533 & 0.111793 & 0.0792 & 0.188276 & 0.141234 & 0.103512 & 0.073333 \\
\hline 0.4 & 0.187696 & 0.140799 & 0.103193 & 0.073108 & 0.173793 & 0.130369 & 0.095549 & 0.067693 \\
\hline 0.5 & 0.167586 & 0.125714 & 0.092137 & 0.065275 & 0.155172 & 0.116402 & 0.085312 & 0.060444 \\
\hline 0.6 & 0.143007 & 0.107276 & 0.078623 & 0.055701 & 0.132414 & 0.09933 & 0.072799 & 0.051575 \\
\hline
\end{tabular}

Table II: Velocity of gas at $\mathrm{t}=0.1,0.2$

\begin{tabular}{|c|c|c|c|c|c|c|c|c|}
\hline \multirow[b]{3}{*}{$\mathrm{R}$} & \multicolumn{8}{|c|}{$\mathrm{U}$} \\
\hline & \multicolumn{2}{|c|}{$n=0.9$} & \multicolumn{2}{|c|}{$\mathrm{n}=0.8$} & \multicolumn{2}{|c|}{$\mathrm{n}=0.7$} & \multicolumn{2}{|c|}{$\mathrm{n}=0.6$} \\
\hline & $t=0.1$ & $t=0.2$ & $t=0.1$ & $t=0.2$ & $t=0.1$ & $t=0.2$ & $t=0.1$ & $t=0.2$ \\
\hline 0.1 & 0.221214 & 0.241324 & 0.165943 & 0.181029 & 0.121621 & 0.132677 & 0.086163 & 0.093996 \\
\hline 0.2 & 0.21451 & 0.234012 & 0.160914 & 0.175543 & 0.117935 & 0.128656 & 0.083552 & 0.091147 \\
\hline 0.3 & 0.203338 & 0.221823 & 0.152533 & 0.166399 & 0.111793 & 0.121955 & 0.0792 & 0.086399 \\
\hline 0.4 & 0.187696 & 0.20476 & 0.140799 & 0.153599 & 0.103193 & 0.112574 & 0.073108 & 0.079754 \\
\hline 0.5 & 0.167586 & 0.182822 & 0.125714 & 0.137143 & 0.092137 & 0.100513 & 0.065275 & 0.071209 \\
\hline 0.6 & 0.143007 & 0.156008 & 0.107276 & 0.117028 & 0.078623 & 0.085771 & 0.055701 & 0.060765 \\
\hline
\end{tabular}

Retrieval Number: C8012019320/2020@BEIESP DOI: 10.35940/ijitee.C8012.01932020 Journal Website: www.ijitee.org
Fig.4. Velocity of gas and dust particles for distinct values of $\mathbf{n}$ under exponential pressure gradient.

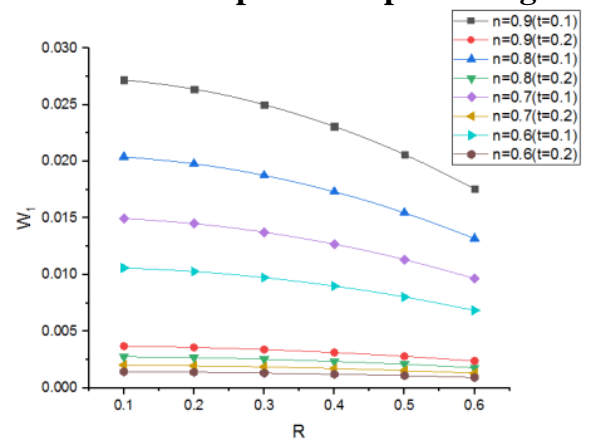

Fig.5. Velocity of gas for distinct values of $n$ w.r.t. time $t$.

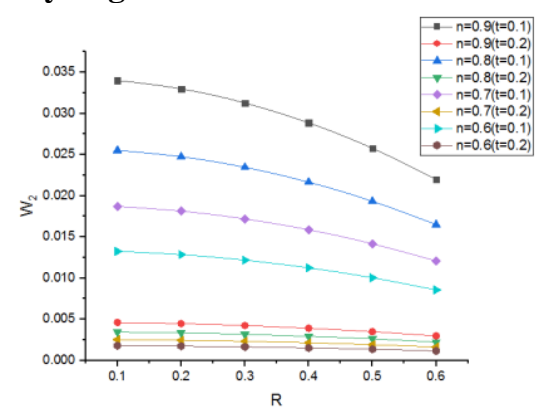

Fig.6. Velocity of dust particles for distinct values of $\mathbf{n}$ w.r.t. time t. 
Unsteady Flow of a Dusty Gas Through a Horizontal Pipe with Time Varying Pressure Gradient

Table III: Velocity of dust particles at $\mathbf{t}=\mathbf{0 . 1 , 0 . 2}$

\begin{tabular}{|c|c|c|c|c|c|c|c|c|}
\hline \multirow[b]{3}{*}{$\mathrm{R}$} & \multicolumn{8}{|c|}{ V } \\
\hline & \multicolumn{2}{|c|}{$n=0.9$} & \multicolumn{2}{|c|}{$\mathrm{n}=0.8$} & \multicolumn{2}{|c|}{$\mathrm{n}=0.7$} & \multicolumn{2}{|c|}{$n=0.6$} \\
\hline & $t=0.1$ & $t=0.2$ & $t=0.1$ & $t=0.2$ & $t=0.1$ & $t=0.2$ & $t=0.1$ & $t=0.2$ \\
\hline 0.1 & 0.204828 & 0.223448 & 0.153651 & 0.167619 & 0.112612 & 0.122849 & 0.79981 & 0.087033 \\
\hline 0.2 & 0.19862 & 0.216678 & 0.148994 & 0.16254 & 0.109799 & 0.119126 & 0.077363 & 0.084395 \\
\hline 0.3 & 0.188276 & 0.205392 & 0.141234 & 0.154073 & 0.103512 & 0.112921 & 0.073333 & 0.079999 \\
\hline 0.4 & 0.173793 & 0.189593 & 0.130369 & 0.142221 & 0.095549 & 0.104235 & 0.067693 & 0.073846 \\
\hline 0.5 & 0.155172 & 0.16928 & 0.116402 & 0.126984 & 0.085312 & 0.093068 & 0.06044 & 0.065934 \\
\hline 0.6 & 0.132414 & 0.144452 & 0.09933 & 0.108359 & 0.072799 & 0.079418 & 0.051575 & 0.056264 \\
\hline
\end{tabular}

Table IV : Velocities of gas and dust particles under exponential pressure gradient

\begin{tabular}{|c|c|c|c|c|c|c|c|c|}
\hline & \multicolumn{5}{|c|}{$\mathrm{W}_{1}$} & \multicolumn{4}{c|}{$\mathrm{W}_{2}$} \\
\hline $\mathrm{R}$ & $\mathrm{n}=0.9$ & $\mathrm{n}=0.8$ & $\mathrm{n}=0.7$ & $\mathrm{n}=0.6$ & $\mathrm{n}=0.9$ & $\mathrm{n}=0.8$ & $\mathrm{n}=0.7$ & $\mathrm{n}=0.6$ \\
\hline 0.1 & 0.027217 & 0.020417 & 0.014963 & 0.010601 & 0.034021 & 0.025521 & 0.018704 & 0.013251 \\
\hline 0.2 & 0.026393 & 0.019798 & 0.014509 & 0.010279 & 0.032991 & 0.024748 & 0.018136 & 0.012849 \\
\hline 0.3 & 0.025017 & 0.018767 & 0.013754 & 0.009744 & 0.031271 & 0.023459 & 0.017193 & 0.01218 \\
\hline 0.4 & 0.023093 & 0.017323 & 0.012696 & 0.008995 & 0.028866 & 0.021654 & 0.01587 & 0.011244 \\
\hline 0.5 & 0.020619 & 0.015467 & 0.011336 & 0.008031 & 0.025774 & 0.091334 & 0.01417 & 0.010039 \\
\hline 0.6 & 0.017594 & 0.013199 & 0.009673 & 0.006853 & 0.021993 & 0.016499 & 0.012091 & 0.008566 \\
\hline
\end{tabular}

Table V: Velocity of gas at $t=0.1,0.2$

\begin{tabular}{|c|c|c|c|c|c|c|c|c|}
\hline \multirow{2}{*}{} & \multicolumn{7}{|c|}{} & \multicolumn{2}{c|}{$\mathrm{V}_{1}$} & \multicolumn{2}{c|}{$\mathrm{n}=0.7$} \\
\cline { 2 - 9 } & \multicolumn{2}{|c|}{$\mathrm{n}=0.9$} & \multicolumn{2}{|c|}{$\mathrm{n}=0.8$} & $\mathrm{n}=0.6$ \\
\hline $\mathrm{R}$ & $\mathrm{t}=0.1$ & $\mathrm{t}=0.2$ & $\mathrm{t}=0.1$ & $\mathrm{t}=0.2$ & $\mathrm{t}=0.1$ & $\mathrm{t}=0.2$ & $\mathrm{t}=0.1$ & $\mathrm{t}=0.2$ \\
\hline 0.1 & 0.027217 & 0.003684 & 0.020417 & 0.002763 & 0.014963 & 0.002025 & 0.010601 & 0.001435 \\
\hline 0.2 & 0.026393 & 0.003572 & 0.019798 & 0.002679 & 0.014509 & 0.001964 & 0.010279 & 0.001391 \\
\hline 0.3 & 0.025017 & 0.003386 & 0.018767 & 0.002539 & 0.013754 & 0.001862 & 0.009744 & 0.001319 \\
\hline 0.4 & 0.023093 & 0.003126 & 0.017323 & 0.002344 & 0.012696 & 0.001719 & 0.008995 & 0.001217 \\
\hline 0.5 & 0.020619 & 0.002791 & 0.015467 & 0.002093 & 0.011336 & 0.001535 & 0.008031 & 0.001087 \\
\hline 0.6 & 0.017594 & 0.002381 & 0.013199 & 0.001786 & 0.009673 & 0.001309 & 0.006853 & 0.000927 \\
\hline
\end{tabular}

Table VI: Velocity of dust particles at $\mathrm{t}=\mathbf{0 . 1 , 0 . 2}$

\begin{tabular}{|c|c|c|c|c|c|c|c|c|}
\hline \multirow[b]{3}{*}{$\mathrm{R}$} & \multicolumn{8}{|c|}{$W_{2}$} \\
\hline & \multicolumn{2}{|c|}{$\mathrm{n}=0.9$} & \multicolumn{2}{|c|}{$\mathrm{n}=0.8$} & \multicolumn{2}{|c|}{$\mathrm{n}=0.7$} & \multicolumn{2}{|c|}{$n=0.6$} \\
\hline & $\mathrm{t}=0.1$ & $\mathrm{t}=0.2$ & $\mathrm{t}=0.1$ & $\mathrm{t}=0.2$ & $\mathrm{t}=0.1$ & $\mathrm{t}=0.2$ & $\mathrm{t}=0.1$ & $\mathrm{t}=0.2$ \\
\hline 0.1 & 0.034021 & 0.004605 & 0.025521 & 0.003454 & 0.018704 & 0.002531 & 0.013251 & 0.001794 \\
\hline 0.2 & 0.032991 & 0.004465 & 0.024748 & 0.003349 & 0.018136 & 0.002455 & 0.012849 & 0.001739 \\
\hline 0.3 & 0.031271 & 0.004233 & 0.023459 & 0.003174 & 0.017193 & 0.002328 & 0.01218 & 0.001649 \\
\hline 0.4 & 0.028866 & 0.003908 & 0.021654 & 0.00293 & 0.01587 & 0.002149 & 0.011244 & 0.001521 \\
\hline 0.5 & 0.025774 & 0.003489 & 0.019334 & 0.002616 & 0.01417 & 0.001919 & 0.010039 & 0.001359 \\
\hline 0.6 & 0.021993 & 0.002976 & 0.016499 & 0.002233 & 0.012091 & 0.001636 & 0.008566 & 0.001159 \\
\hline
\end{tabular}

Retrieval Number: C8012019320/2020@BEIESP DOI: 10.35940/ijitee.C8012.01932020 Journal Website: www.ijitee.org
Published By:

630 Blue Eyes Intelligence Engineering \& Sciences Publication 


\section{CONCLUSION}

In this paper, the velocity of gas and dust particles is obtained for different values of parameter $\mathrm{n}$ at time $\mathrm{t}$. Equations (22),(23) and (36),(37) represent the velocity of gas and dust particles under the effect of linear and exponential pressure gradient respectively shown in Figs. 16 which concluded that velocities increases as one move towards the axis of the pipe. Under linear pressure gradient velocity of the gas is greater than the velocity of the dust particles. Under the exponential pressure gradient velocity of the dust particles is greater than the velocity of the gas.

\section{REFERENCES}

1. A.Damesh Rebhi, "On boundary layer flow of a dusty gas from a horizontal circular cylinder”, Brazil J. Ch. Engrg., 27 ,2010, pp. 653662.

2. G.Narsimlu; L.Anand Babu and P.Raji Reddy, "The flow of a dusty viscous liquid through circular cylinder", Pelagia Research Lib. 5,2011, pp. 416-420.

3. M.Allan Fathi; Qatanani Naji; Barghouthi Imad and M.Takatka Khaled, "Dusty gas model of flow through naturally occurring porous media", App. Math. \& Comp., 148 ,2004, pp. 809-821.

4. M.H.Hamdan and R.M.Barron, "A dusty gas flow model in porous media", J. Com. \& App. Math,. 30 ,1990, pp. 21-37.

5. M.S.Abu Zaytoon and M.H.Hamdan, "The flow of a Saffman's dusty gas with pressure dependent viscosity through porous media", Elixir Appl. Math.98 ,2016, pp. 42550-42554.

6. P.G.Saffman, "On the stability of laminar flow of a dusty gas", J. Fluid Mech. 13, 1962, pp. 120-128.

7. P.Samba Siva Rao, "Unsteady flow of a dusty viscous liquid through circular cylinder”, 19 ,1968, pp. 135-138.

8. Praveen Sharma and C.L.Varshney, "Thermal dispersion effect on MHD flow of dusty gas and dust particles through the hexagonal channel", Int. J. Heat and Mass Transfer 46,2003, pp. 2511-2514.

9. R.K.Gupta and S.C.Gupta, "Flow of a dusty gas through a channel with arbitrary time-varying pressure gradient", J. App. Math. \& Phys. 27,1976 , pp. 119-125.

\section{AUTHORS PROFILE}

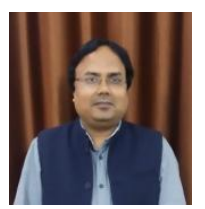

Dr. Madan Lal, has completed M.Sc. degree in Mathematics in the year 1997 from M.J.P.Rohilkhand University, Bareilly (U.P.) India. and cleared NET (CSIR JRF) examination in december 2001. Ph.D. degree was awarded to him in 2003 (Mathematics) on the topic "Some Problems on Hydrodynamics and MHD flows" and his more than 15 research papers on "Magnetohydrodynamics" has been published in reputed National/International journals. He has participated more than 10 National /International conferences /workshops/seminars etc. Dr. Lal also chaired the session in various National and International conferences. He is also the life member of Indian Science Congress Association, Indian Mathematica Society etc. Currently he is working as Head of Applied Mathematics Department, M.J.P.Rohilkhand University Bareilly (U.P.) India.

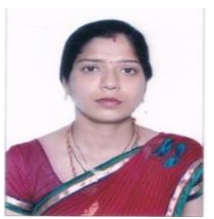

Swati Agarwal, has completed M.Sc. degree in Mathematics in the year 2008 from M.J.P.Rohilkhand University, Bareilly (U.P.) India. and cleared NET examination in 2010. Author has joined for Ph.D. degree in Mathematics on the topic "Study on Magnetohydrodynamic Turbulence." in the year 2014 and three research papers has been published in National/International journals . She has also participated National /International conferences /workshops/seminars. She is the life member of Indian Science Congress Association and Indian Mathematical Society. 